\title{
ENVISIONING HISTORY - THE ROLE OF DIGITAL TECHNOLOGIES IN DOCUMENTING LOST ARCHITECTURAL HERITAGE
}

\author{
Giuseppe Mazzone \\ Asst. Prof. Dr., University of Notre Dame, INDIANA - U.S.A., gmazzone@nd.edu
}

\begin{abstract}
Digital technologies occupy an essential part of today's activities and teaching practices. Architecture is not an exception. However, where CAD applications supply precision and three dimensional support for creating new designs, the study of architectural heritage tends to be dependent from laser scanning machines. The dependance from physical artifacts becomes therefore a pre-requisite for similar studies posing issues when the analyzed subjects are no long existing. A critical analysis of surviving graphic documentations becomes thus the starting point for a reconstruction. The procedure can be compared to an actual design process with each component individually analyzed and three-dimensionally modeled. The resulting product moves away from massing models to promoted instead a tectonic reconstruction of a selected building combining architectural history, historic preservation, and structural design.
\end{abstract}

The case study on which these technique was tested is an unbuilt baroque church, Sainte-Anne-la-Royale in Paris. The project was originally developed in 1662 by the Italian architect Guarino Guarini and is currently documented by three engravings only: a plan of the first level, a transverse section, and main elevation. The mismatching information between views required a deep understanding of Guarini's design architectural principles and compositional methods. The several theoretic information surrounding the building were graphically translated and critically interpreted to offer reliable graphic references for the church. The procedure required the identification of a coherent geometric setting linking every element in the building; a study of the individual take Guarini offered about architectural orders; the analysis and modeling of every architectural component present in the building.

The results of the research are presented through multiple outputs: handmade drawings, digital drawing, 3D digital models, 3D printed models, a VR real scale model of the church fully textured. The research offers a valuable insight on the implementation of digital technologies in architectural pedagogy. The tectonic reconstruction here promoted combines theory with practice linking several aspect of the scholastic formation in architectural schools while enhancing interactivity in the study of architectural heritage.

Keywords: Research projects, Digital reconstructions, Architectural Heritage, Baroque Architecture, 3D Modelling, Innovation

\section{INTRODUCTION}

Architectural practice has been slowly reshaped by the introduction of CAD software. While a constant improvement in methods and results represents the first step towards evolution, traditional design practices should not be entirely abandoned by the introduction of the new media. In the case of three-dimensional modeling, the choice to preserve a background in descriptive geometry does not imply a rejection of contemporary applications. It promotes instead a methodology aimed at improving precision while maintaining a traditional workflow. 
From these principles, it was here attempted the reconstruction of a classical building: Sainte-Anne-laRoyale, a medium size church planned in 1662 in Paris by the Italian architect Guarino Guarini. Never completed and later destroyed, Sainte-Anne is documented at the present time by only three engravings: a plan of its figure ground, a transversal section, and the main elevation. The challenge here is to combine traditional drawing techniques with digital technologies, creating a three-dimensional reconstruction of Sainte-Anne in line with its original design and structural properties.

\section{A CRITICAL APPROACH TO GUARINI'S VISION FOR SAINTE-ANNE-LA-ROYALE}

Sainte-Anne did not conform to the principles aimed at by seventeenth century French architecture. The language defining the building descends from the often revered heritage of the Italian Renaissance combined with principles deeply rooted in philosophy and mathematics. A theologian and priest, its designer Guarino Guarini embedded his works with mathematical proportions and geometric progressions in an era when science and faith were in conflict. Member of the Theatine Order from age fifteen, Guarini wrote extensively about the nature of the universe and the role man played in it. As divine creation, the perfection of the cosmos was perceived through Geometry and discernible through Mathematics. The act of studying and understanding the universe and its hidden rules therefore epitomized the apotheosis of knowledge, the virtue God gifted humans with.

By embodying such beliefs, Guarini's architectural designs bloom from pure geometric schemes to tangled volumes in constant interaction with one another. Aches warp along curved surfaces; vaults bend according to radial settings; domes are segmented by interlaced ribs. The final designs, reminiscent of biological organisms, calls to mind the act of creation. Even architectural orders break free from Renaissance standards to embrace variable proportions as noted by Vitruvius in Roman and Greek architecture. Reducing the five orders to their original triad (Doric, lonic, and Corinthian), Guarini offers each in three variations with the option for further customization thanks to interchangeable details and components.

Planned for the city of Paris, Sainte-Anne-la-Royale represents Guarini's first attempt to translate these ideas into a comprehensive design. The church, however, had to adapt to structures enveloping the site and to already existing foundations of a previous discarded design for the same building. Following the request for scenographic devices by the Theatines, the religious order requesting the design, Guarini encompassed the site's physical constraints with a telescopic structure: an interlaced ribbed dome surmounted by an octagonal pavilion vault with lantern (Fig. 1). This towering complex rises above a diaphanous gallery whose circular layout is planned according to perspective illusions. Only when perceived from the bottom of the central bay does its ratio of 3 to 1 , height to width, reveal a balanced composition while, in reality, its components are far beyond human proportions (Figg. 2, 3).
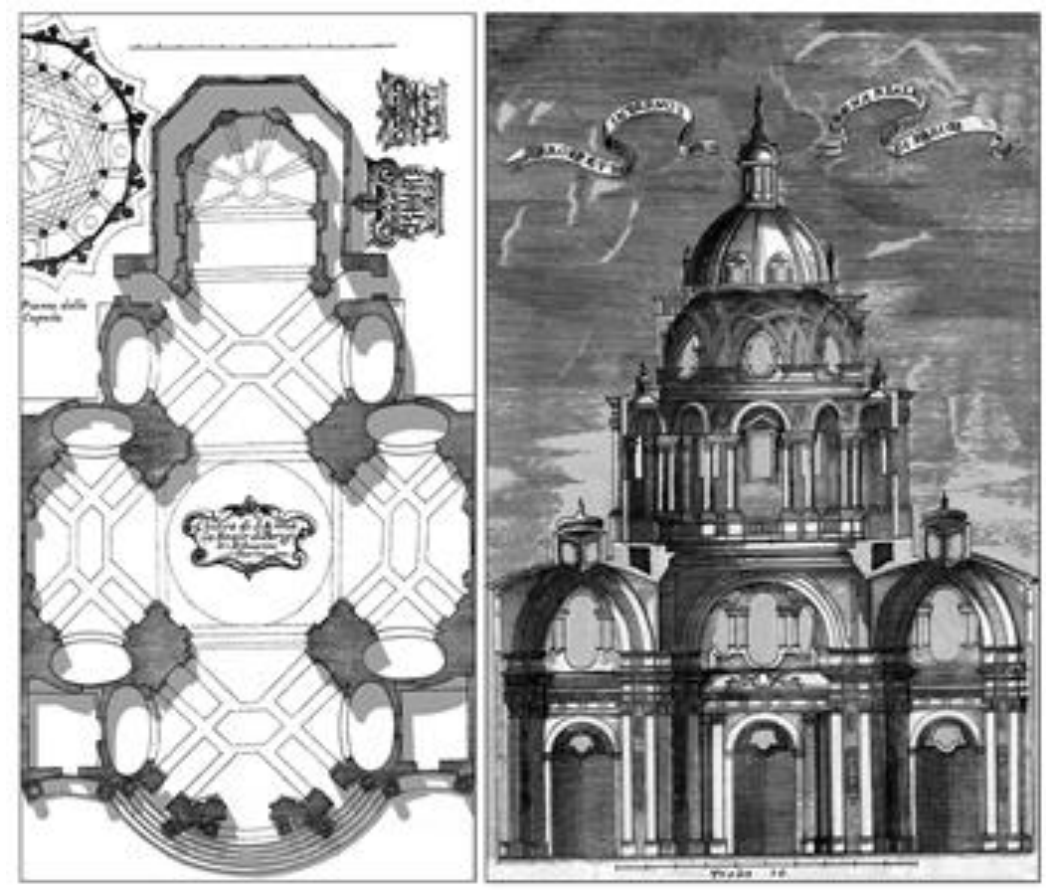

Fig. 1. Plan (left) and section (right) of Sainte-Anne-la-Royale, Paris, France. Guarino Guarini, 1662. Engravings from Architettura Civile (1737), plates 9, 11 


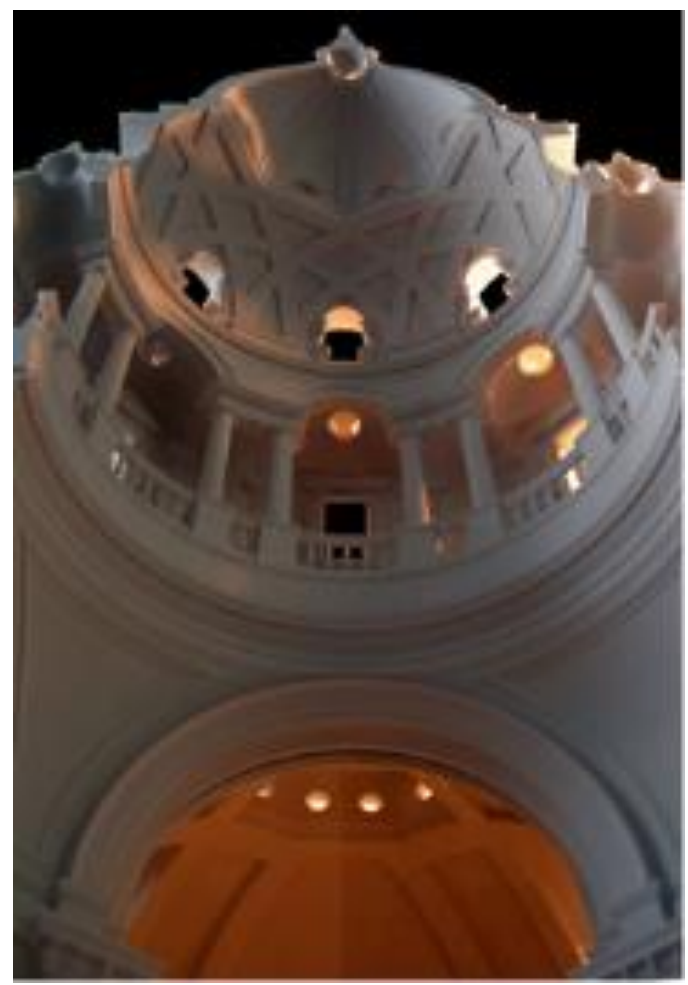

Fig. 2. View of the third level gallery from the first level central bay in the 3d printed model of Sainte-Anne-laRoyale (Picture and model by the author)

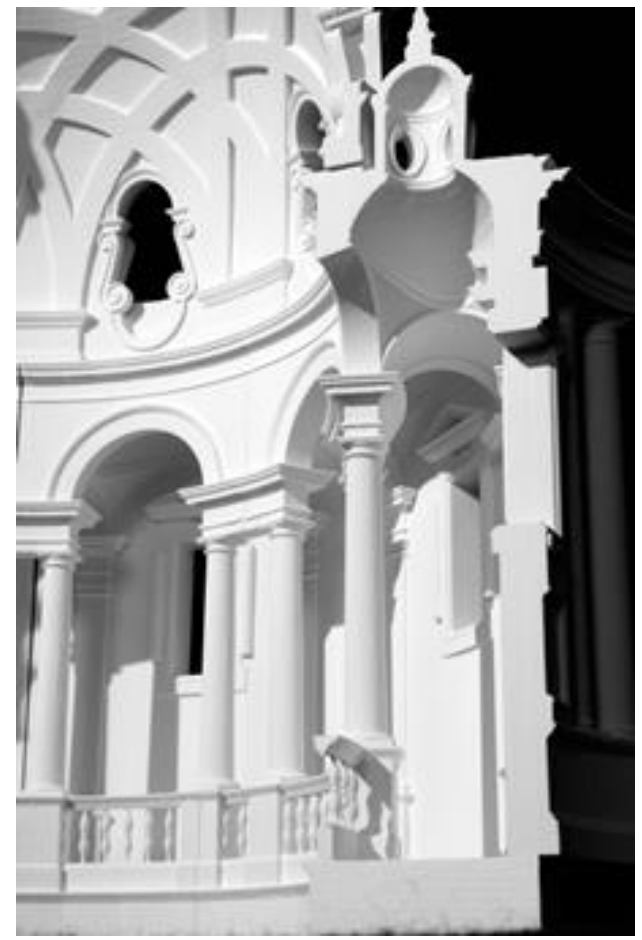

Fig. 3. Frontal view of the third level gallery in Sainte-Anne-la-Royale showing the real proportions of the level (Picture and model by the author)

On the levels below, the radial scheme separates into two components: a diagonal one, structuring the layout of the side bay vaults; and an orthogonal one, individuating the church's main circulation. While moving along the church's orthogonal axes, the view of the observer focuses on the pilaster strips articulating the diagonal pillars bounding the central bay. Their elongated profile, taller than traditional columns, directs attention towards the spaces above where a multi-tier circular structure - a shrine for the soul - floats above slender columns. 
Permeating each and every aspect of the composition, the geometric purity of the design is altered by the surrounding buildings. The symmetry radiating from the central bay contracts along the transept causing an asymmetrical layout in the church's diagonal pillars. As a consequence, the vaults in the transversal bays become shallower than their longitudinal counterparts. In the original elevation engraving, the mismatching height of longitudinal and transversal vaults is conveniently overlooked by omitting the lantern crowning the church's entrance bay. Likewise, in the section engraving, the circular gallery aligns with the traversal vaults which, lower than the longitudinal ones, causes a structural clash along the church's longitudinal axis. To solve the issue without drastically altering the original design, the original alignment in the engraving was applied on the longitudinal axis thus raising the height of the galley. The resulting void was filled by introducing a podium, while originally the gallery sits directly on top of the pendentive's entablature.

Similar issues both compositional and structural in nature pervade Sainte-Anne's original graphic documentation. Elements supposedly symmetric are irregularly rendered; parallel lines bend due to graphic imprecision; volumes are discordant between views or are entirely omitted; architectural details are extensively simplified or overlooked (Fig. 4). Before attempting a reconstruction for the church, it was therefore necessary to create a new set of drawings focusing on:

1. Understanding the geometric matrix structuring the design while including and justifying the deformation caused by existing buildings on adjacent lots;

2. Correcting mismatching elements between views in the original engravings and implementing them in a coherent scheme;

3. Updating the design by including areas, elements, and details not visible or missing in the original graphic sources.
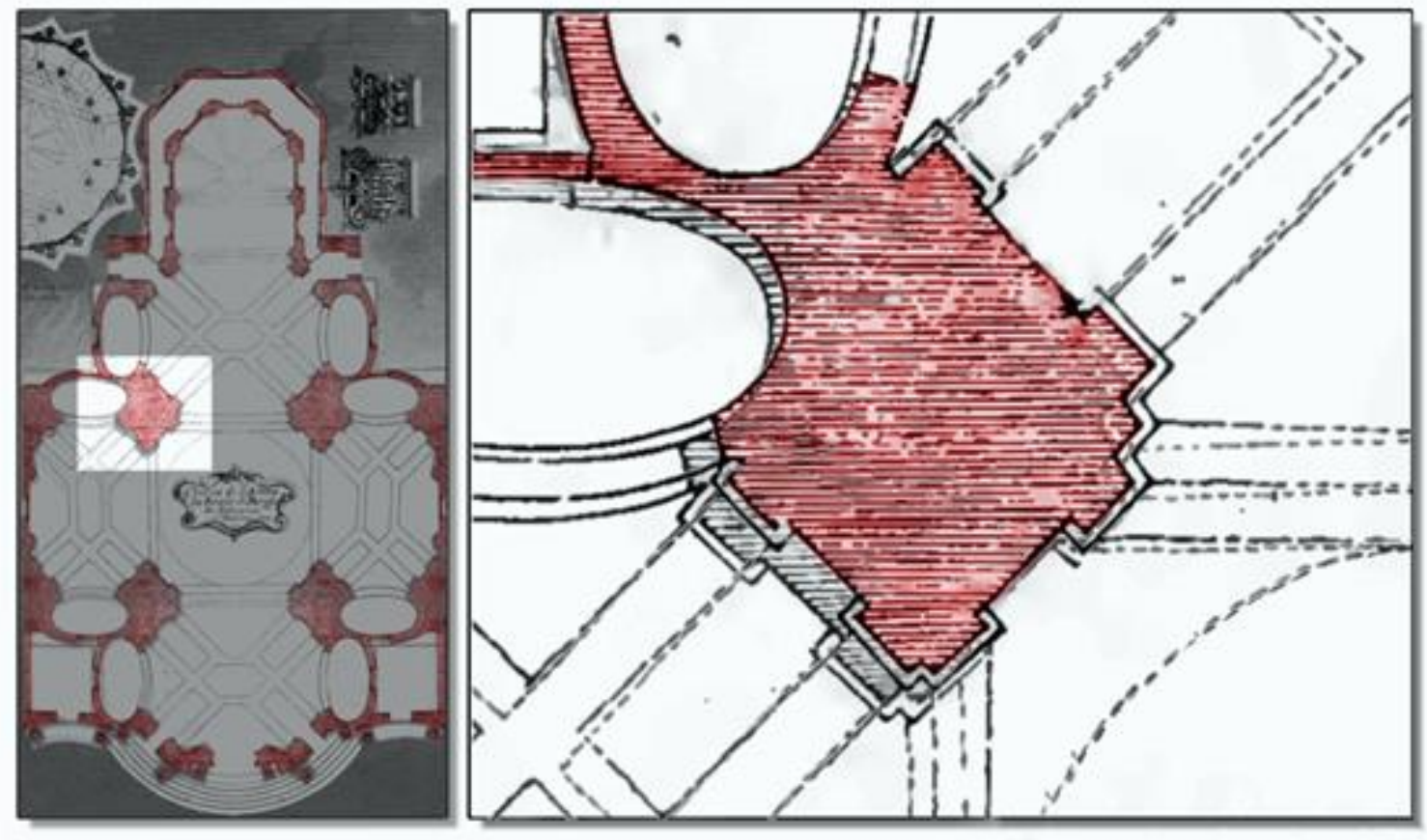

Fig. 4. Example for the lack of symmetry in the northwest pillar (in gray) when overlapped to the north east one (in red) (Drawing by the author on Guarini's engraving from Architettura Civile).

\section{METHODOLOGY}

The remarkable precision afforded by CAD software proved a valuable aid for the procedure while digital technologies improved visualization and realization of the research results. As architects we are trained to imagine spaces and volumes by looking at plans, sections, elevations - a set of skills which is not necessarily shared by public outside the profession. Thanks to the versatility of digital technologies, these mental pictures were translated into more commonly understood visual artefacts presented in a wide variety of formats: traditional and digital drawings, animations, interactive digital models, and 3D printed models. 
The reconstruction started by developing a new figure ground for the church. Drawn directly on top of the original engravings, which were imported into a CAD environment, these drawings offered a constant reference for the composition and proportion of new updated building plans. The circle inscribed in the church's central bay was chosen as starting element for identifying a geometric scheme for the building. This element corresponds to already execute foundations coming from a previous design for the same church realized by Mazarin's private artist, Antonio Maurizio Valperga. By applying basic methods like squaring of the circle and geometric projections, every component of the design was inscribed in a coherent scheme encompassing the church's figure ground to include all the levels composing the building (Fig. 5).

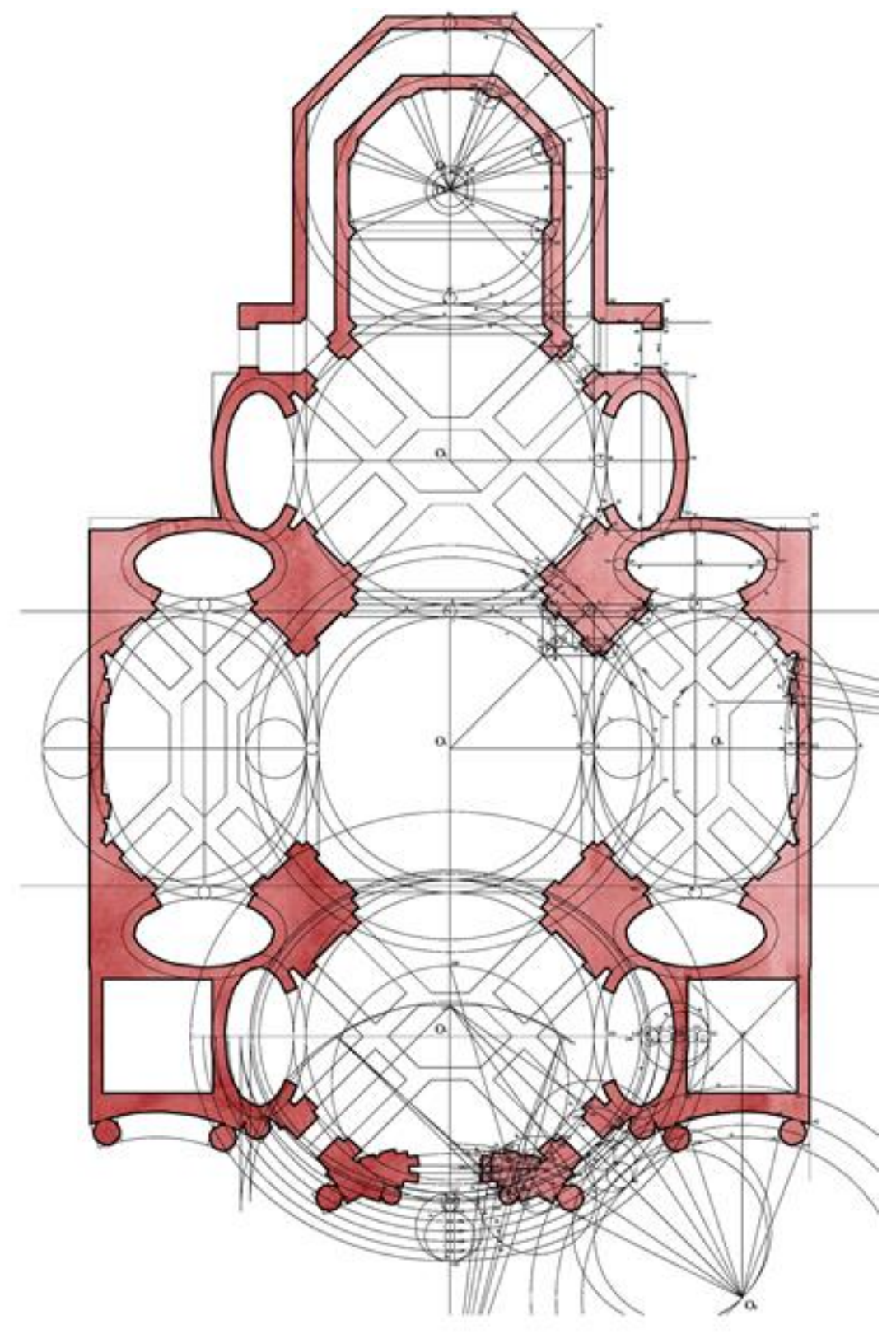

Fig. 5. Reconstructed plan for Sainte-Anne-la-Royale. (Drawing by the author)

The analysis moved then to the section and elevation - the geometric matrix combined to the proportional system structuring the architectural orders. The base module for main and secondary orders, identified in plan, was multiplied combining the directions contained in the engravings and the suggestions contained in Architettura Civile - Guarini's posthumous architectural essay. Additional details and proportions not supplied by these sources came from the analysis of Guarini's other designs (Fig. 6).

With this information, a set of measure drawings focusing on Sainte-Anne's main features was created. Their combination with the updated plans offered the base for developing an accurate three-dimensional rendition of the church. The method guiding the procedure followed the rules of stereotomy, the French art of stone 
cutting, the technique Sainte-Anne was supposed to be built with. Strongly based on orthographic projections, stereotomic applications found a perfect match in the high precision offered by CAD software. Each component in the building was therefore analyzed and graphically described by multiple projection planes - the complexity of the procedure related to the nature of each individual component (Fig. 7).

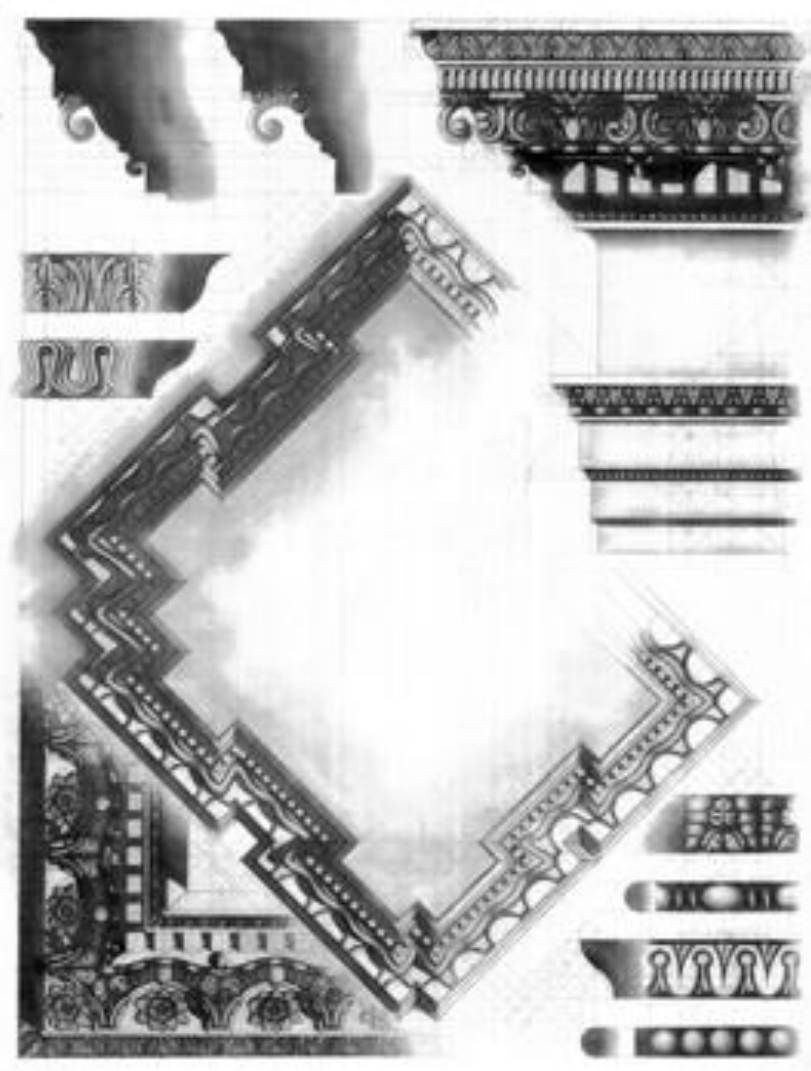

Fig. 6. Analysis and reconstruction of the pillar's entablature (Drawing by the author - graphite on mylar).

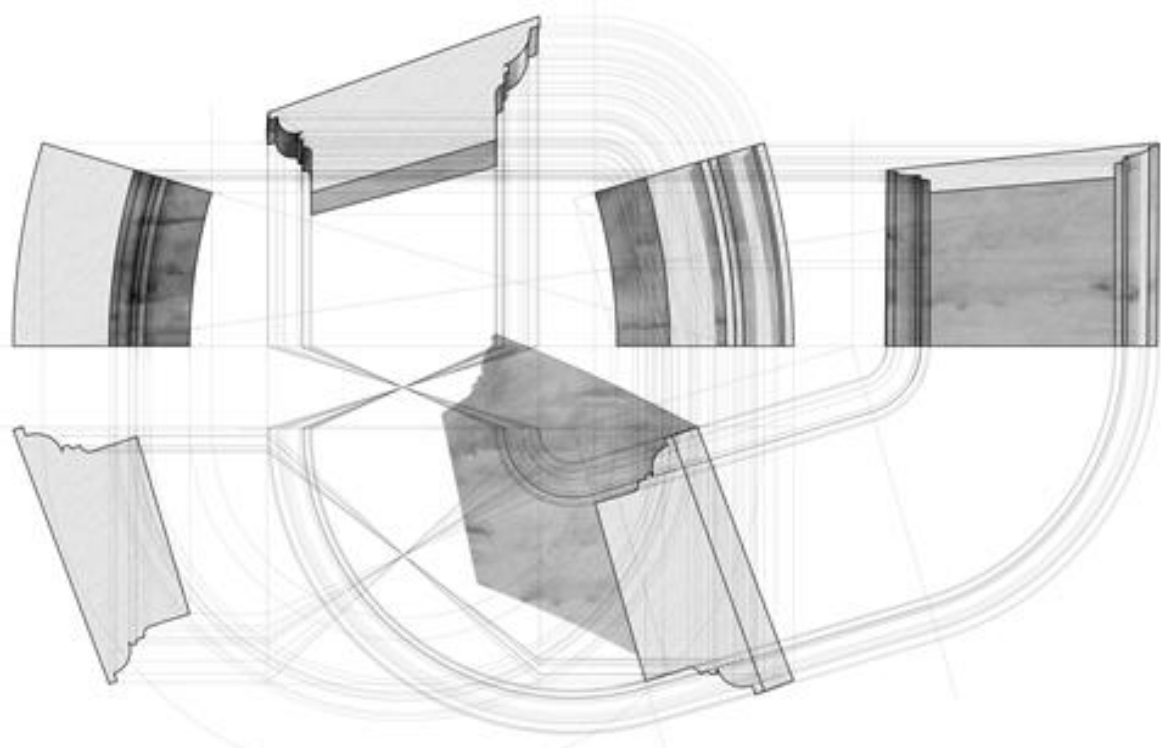

Fig. 7. Voissour from the first level arch accessing the elliptical chapels showing how each component in the building has been individually analyzed and modeled (Drawing by the author). 


\section{VIRTUAL ENVIRONMENT AND RAPID PROTOTYPING}

The resulting digital model was then imported into a three-dimensional immersive environment, Sainte-Anne became accessible for the very first time. Implementations of secondary areas and subsidiary spaces further improved the church's accessibility together with the option to move the camera to face vaults and ceilings. Likewise, restrictions due to gravity were overcome by levitating the observer beyond the ground level exploring areas previously inaccessible (such as the third level circular gallery and the roofs).

To preserve the principles leading the reconstruction, a combination of digital and traditional techniques was followed also for the model's textures. Photo-realistic stone patterns where therefore combined with handmade drawings of moldings and carvings preserving a hand-crafted quality to the model (Fig. 8).

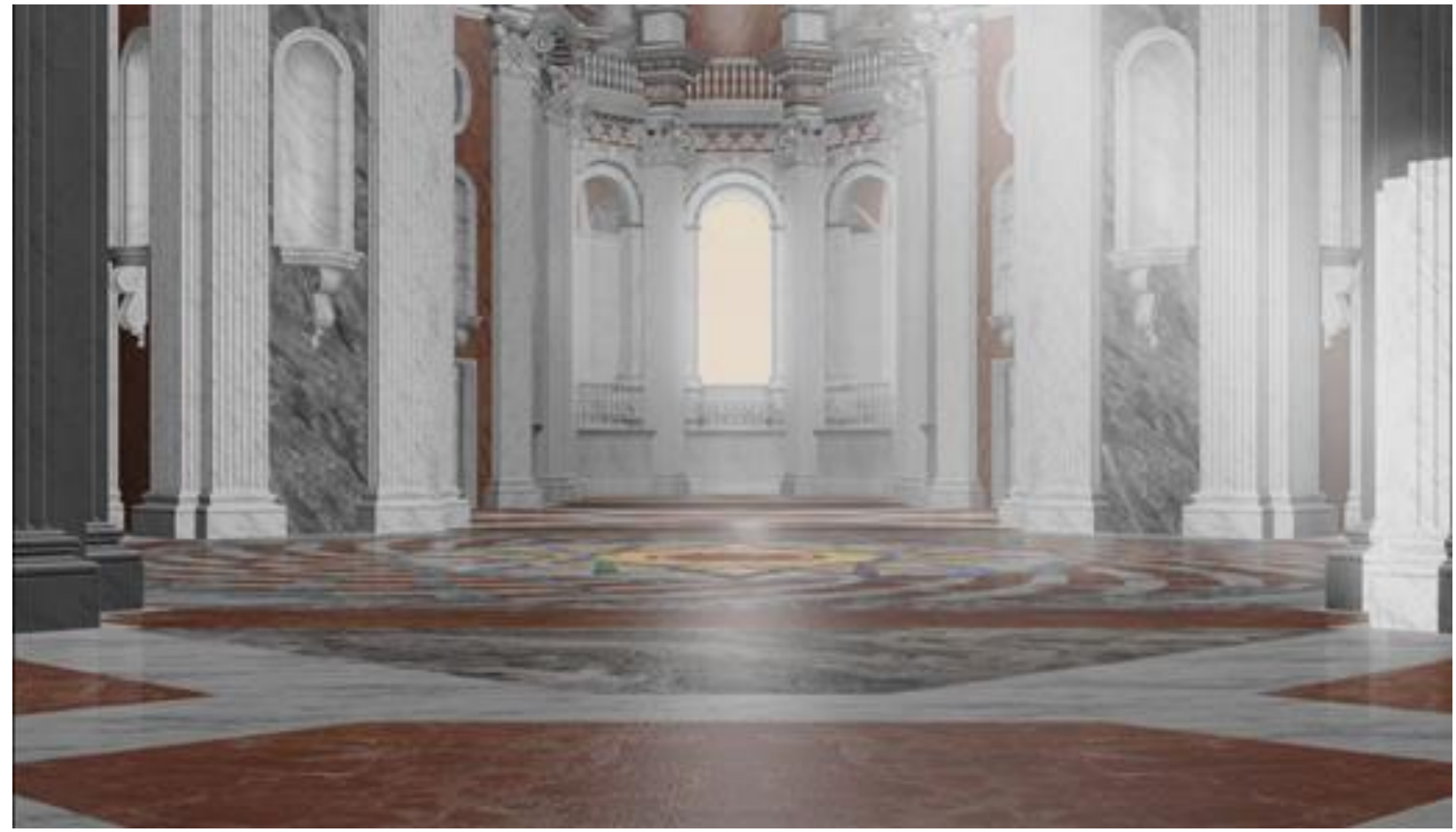

Fig. 8. View from the entrance bay towards the altar bay in the Virtual Reality model for Sainte-Anne-la-

Royale (Picture by the author)

Outside the immersive environment, accessibility to the project was obtained by rendering several videos along established paths. While reducing the chance of interaction, these videos gave the chance to display the research in lectures, exhibitions, and websites.

At last, a physical rendition of the church was obtained by processing the three-dimensional model into a 3D printer. To offer a direct comparison between the church's reconstruction and its original engravings, a version of the model deprived of textures was sliced along its transversal axis (Fig. 9). Divided in smaller components, this model was processed through a gypsum powder 3D printer creating a large scale physical model. The display gave also the opportunity to study Sainte-Anne's natural light thanks to strategically located spot lights. The study indicated the role performed by the second level elliptical chapels in distributing natural light along Sainte-Anne's indoor surfaces - the chapels becoming almost lantern glowing with light (Fig. 10).

\section{CONCLUSIONS}

Similar results would have been hardly achieved with traditional techniques only. At the same time, digital drawing techniques would have not been able to precisely create such complex surfaces without a traditional stereotomic approach. Even if considered by many at the opposite sides of the same spectrum, this research shows that traditional and contemporary approaches can and should indeed coexist. Gaining strength from each other, their collaboration may open the road to never-ending possibilities, enhancing the latest technologies with lessons coming from thousands years of experience. 


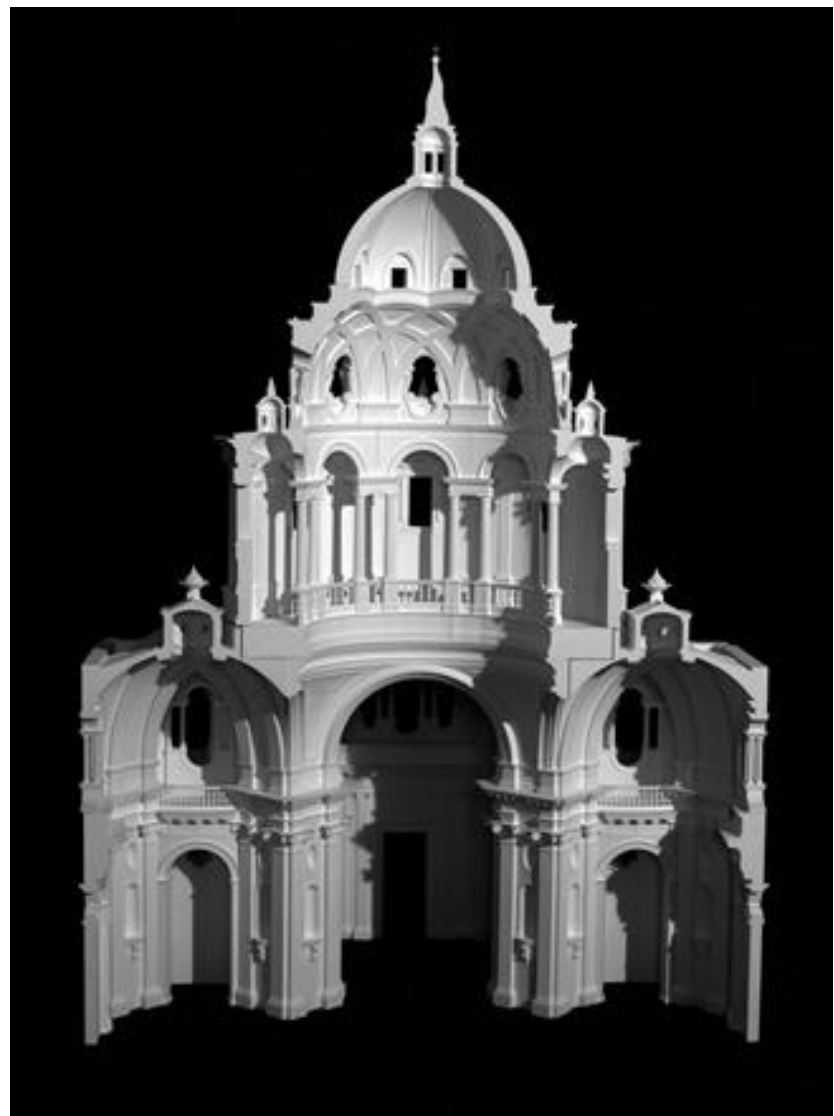

Fig. 9. Sectional 3D printed model of Sainte-Anne-la-Royale (Model and picture by the author)

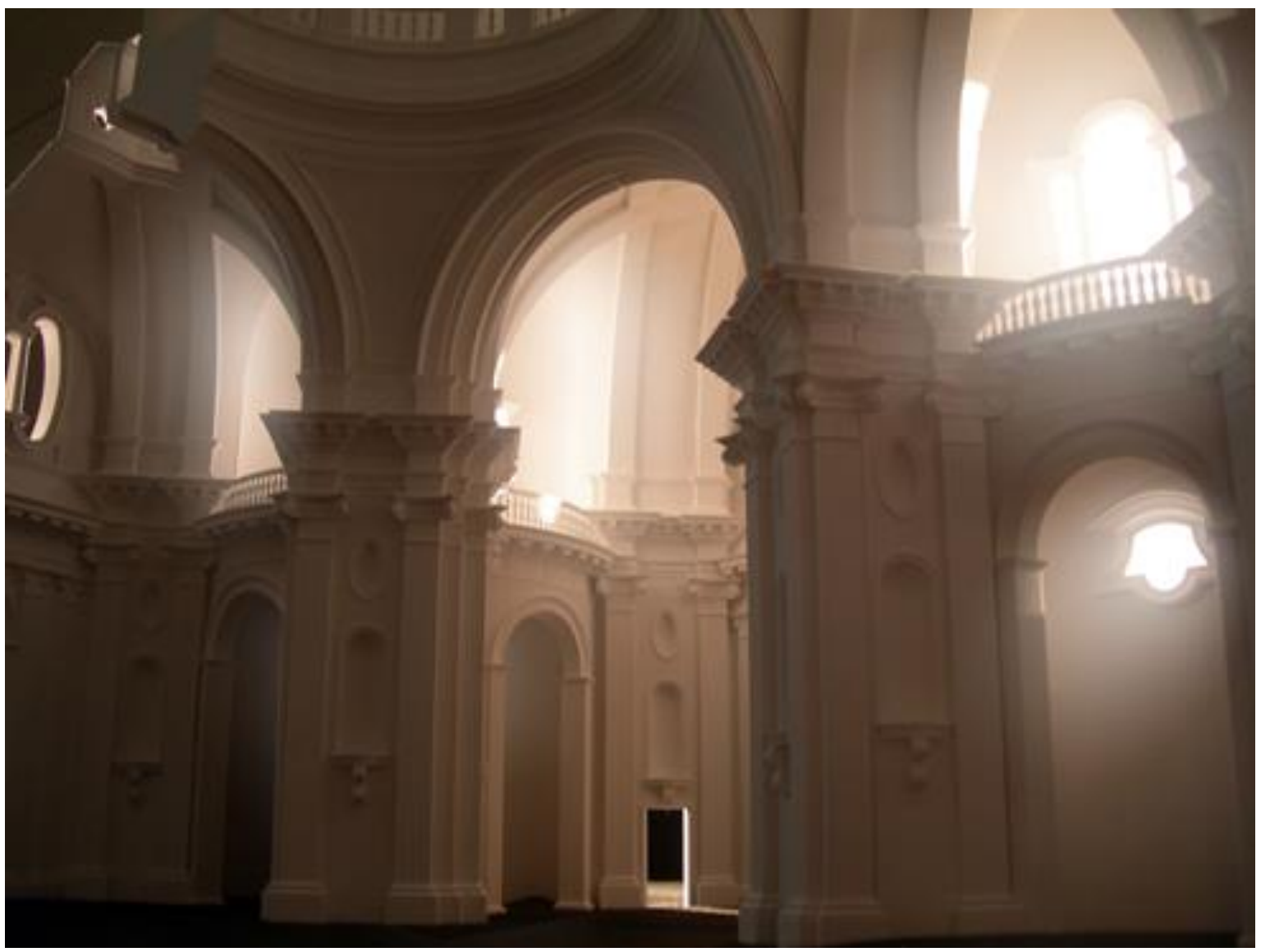

Fig. 10. Study of natural light in Sainte-Anne's 3D printed model (Model and picture by the author). 


\section{REFERENCE LIST}

Coffin, D. (1956). Padre Guarino Guarini in Paris. Journal of the Society of Architectural Historians, 15 (2).

Freguglia, P. (2009). Reflections on the Relationship between Perspective and Geometry in the Sixteenth and Seventeenth Centuries. Nexus Network Journal, XI (3).

Guarini, G. (1738). Architettura Civile, Turin.

Mazzone, G. (2014). Geometry of Faith: a Stereotomic Recosntruction of Sainte-Anne-la-Royale in Paris. Ph.D. Thesis, University of Winsconsin, Milwaukee.

Mueller, W. (1970). Guarini e la stereotomia. Guarino Guarini e l'internazionalità del Barocco. Turin, Accademia delle Scienze.

Passanti, M. (1970). Disegni integrativi di lastre del trattato della «Architettura Civile.». Guarino Guarini e I'Internazionalità del Barocco, Turin, Accademia delle Scienze.

Robinson, E. C. (1991). Optics and Mathematics in the Domes Churches of Guarino Guarini. Journal of the Society of Architectural Historians, 50 (4).

Rosso, F. (2006). Guarino Guarini stereotomista. Guarino Guarini, Turin, Umberto Allemandi \& C.

Sbacchi, M. (2009). Projective Architecture. Nexus Netwotk Journal, XI (3).

Trevisan, C. (2011). Per la storia della stereotomia - Geometrie, metodi e costruzioni. Ph.D. thesis, University IAUV, Venice. 